\title{
Time of Emergence of Permanent Teeth of the Children of Peshawar, Pakistan
}

\author{
Nazeer Khan ${ }^{1}$ \\ Hasham Khan ${ }^{2}$ \\ Mujeeb ur Rehman Baloch ${ }^{3}$
}

Sarfraz Ali Abbasi ${ }^{4}$

\author{
MSc, PhD \\ BDS, MSc \\ BDS, MPH, MPhil \\ BDS, MCPS
}

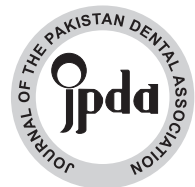

OBJECTIVE: To establish the standard of mean emergence time of permanent teeth, except the third molars, of Pakhtoon children. In addition to find out the effect of gender, weight, height, and body mass index on time of emergence of this ethnic population.

METHODOLOGY: Sample size was calculated as 2000 cases (just erupted teeth) using the study of Karachi. ${ }^{2}$ Twenty-one private and public schools were randomly selected using systematic random sampling from the list of schools of Peshawar. A trained and calibrated team of dentist and assistant visited to the schools on the assigned dates. The students who brought the positive consent from their parents and gave accent to be included in the study were screened for general check-ups. The children with at least one 'just erupted' tooth were taken out for data collection. The clinical examination was conducted and height and weight were measured. These information along with dieting habits were recorded on a prescribed form. Date of birth was obtained from the students' record of the school. Results: 1945 children showed at least one just erupted tooth. 879 (45.2\%) children were males. The mean age of the children was $9.44 \pm 2.44$ years. Right 1 st molar (\# 16) showed the minimum eruption time of 6.6 years in maxillary jaw. The last tooth erupted in this jaw was the left 2nd molar (\#27). The first tooth appeared in mandibular jaw was the right central incisor (\#41) with mean value of 6.5 years. The last tooth erupted in this jaw was right 2nd molar (\#47). Male children showed late eruption as compared to girls in all the teeth, except the incisors. Eighteen teeth showed significantly positive correlation of time of eruption with height, 24 teeth showed significantly positive correlation with weight. The sequence of eruption in maxillary teeth was 6-1-2-4-5-3-7, and sequence of eruption in mandibular teeth was 1-6-2-3-4-5-7.

CONCLUSIONS: Study concludes that children of Peshawar showed early eruption than the children of Karachi and India; however, they had late eruption as compared to African children. These children did not show any clear cut trend with other ethnic groups. This study also agreed with most of the other studies that eruption of girls is earlier than boys.

KEY WORDS: permanent teeth, just erupted tooth, eruption time, Peshawar.

HOW TO CITE: Khan N, Khan H, Baloch MUR, Abbasi SA. Time of emergence of permanent teeth of the children of Peshawar, Pakistan. J Pak Dent Assoc 2019;28(4):154-161.

DOI: https://doi.org/10.25301/JPDA.284.154

Received: 18 June 2019, Accepted: 26 September 2019

\section{INTRODUCTION}

$\mathrm{E}$ mergence time and sequence of permanent teeth are essential resource and facilitation for the dentists working in the fields of orthodontics, oral surgery, dental caries and forensic dentistry. The time duration provided for emergence of each tooth and sequence of eruption help the Operative dentists to decide to retain the

1. Professor, Department of Research, Jinnah Sindh Medical University, Karachi.

2. Professor, Department of Pediatric Dentistry, Khyber College of Dentistry, Peshawar.

3. Professor Department of Preventive/Community Dentistry, Bolan Medical College, Quetta.

4. Formally Senior Dental Surgeon, Chandka Medical College Hospital, Larkana.

Corresponding author: "Dr. Nazeer Khan” < nazeerkhan54@gmail.com > carious tooth using some treatment, like endodontic treatment or fillings etc., or extract the tooth1. Orthodontists depend on the sequence and timing of teeth emergence to plan when to start the orthodontic treatment. The age of the subjects with unknown birth record can be computed using the emergence time of permanent teeth in forensic dentistry, school admission and legal purposes. ${ }^{1}$ However, it is mentioned in the literature that time of teeth eruption depends upon biological and environmental factors; such as gender, ethnicity, physique, eating habits and premature extraction of primary teeth etc.

The information provided to the students for emergence time of permanent teeth in dental colleges of Pakistani is mostly obtained from the European and American literature. ${ }^{2}$ 
However, it has been indicated in the literature that time of eruption differs from population to population and influenced by ethical backgrounds. ${ }^{2}$ To develop the standard of time of eruption in different population, studies have been conducted almost every noteworthy country. In recent past studies have been conducted in Asia (Paksitan ${ }^{2,3}$ Saudi Arabia ${ }^{4-6}$, Iraq ${ }^{7}$, Filipine $^{8}$, Malaysia ${ }^{9}$, India ${ }^{10,11}$, Jorden ${ }^{12}$, Nepal ${ }^{13}$, Syria ${ }^{14}$, and Turkey ${ }^{15}$ ), Europe $\left(\right.$ Spain $^{16}$, Lithuania ${ }^{17}$, Czechoslovakia ${ }^{18}$, and United Kingdom ${ }^{19}$ ), Africa (Ugnada ${ }^{20}$, Nigeria ${ }^{21}$ and Sudan $^{22}$ ), America $\left(\right.$ Mexico ${ }^{23}$ ), and Australasia (New Zealand ${ }^{24}$ ).

Unfortunately, until now no standard has been developed for Pakistani population. As far as authors' knowledge is concerned, only two studies have been published for Pakistani children. One was from Karachi ${ }^{2}$ and other was from Rawalpindi. ${ }^{3}$ One study was published before partition for boys of Lahore ${ }^{25}$ and one study is reported for primary teeth ${ }^{26}$ As it is mentioned above that the time of eruption does not only differ between nations, but also affected due to ethical background. Therefore, there is a need to find out the emergence time of other ethical population of Pakistani. Hence a study was conducted for the children of Peshawar to develop the chart of time and sequence of eruption for Pakhtoon (Pathan) children. The objective of the study was to establish the standard of mean emergence time of permanent teeth, except the third molars, of Pakhtoon children. Furthermore to find out the influence of gender, weight, height, and body mass index on time of emergence of this ethnic population.

\section{METHODOLOGY}

List of private and public schools of Peshawar was collected from the Ministry of Education, Khyber Pakhtunkhwa. Sample size was calculated using the study conducted in Karachi. ${ }^{2}$ Using the time of eruption of boys and girls and minimum difference without zero, the sample size was 1844 with $99.99 \%$ confidence interval and $95 \%$ power of the test. Adding 10\% of non-respondent the estimated sample size was 2000 for the children who had 'a just erupted tooth' (cases). The large confidence level and power of the test ware taken, because this was a prevalence study to establish the standard of eruption of permanent teeth of Khyber Pakhtunkhwa province. It is indicated in the literature that $15-20 \%$ of the children have 'a just erupted tooth'. Therefore we were needed more than 10,000 children to complete the required sample size. Systematic random sampling was utilized to select the schools from the schools list. It was estimated that about 100 cases would be obtained from each school. Nine of them were government (public) schools.
Letters were posted to the selected schools and one of the authors (HK) visited to the schools to arrange the date and time for screening the students and data collection. The team of 2 dentists (one male and one female) and 2 assistants (one male and one female) were hired to collect the data. The team was trained and calibrated against a reference examiner who was master trainer for this multicenter study. The training and calibration were conducting in two phases: (1) showing clinical pictures of erupted teeth to the trainees and (2) training and calibration on the students of a selected school with reference examiner. A male/female dentist and an assistant visited to the school on the assigned date. A consent form was sent the students' parent by the administration before this visit. Those students who brought the positive consent from their parents and gave accent to be included in the study were screened for general check-ups. The children with at least one 'just erupted' tooth were taken out for data collection. The criterion for 'just erupted tooth was: a tooth supposed to have emerged if any part of it was visible in the jaw. The clinical examination was conducted by using dental checkup kit under bright light or clear sunlight. Height in $\mathrm{cm}$ and weight in $\mathrm{kg}$ were measured using digital weighing and height measuring machine after removing the shoes. Further information, regarding the diet pattern of the children was also recorded. Date of birth of all the cases was obtained from the students' record of the school. This research was approved by the Institutional Review Board of Dow University of Health Sciences [IRB-B-147/DUHS-10]. Data were entered into computer using SPSS (ver. 16) and analyzed using summary statistics, two-sample ' $t$ ' and chi-square tests.

\section{RESULTS}

One thousand nine hundred forty five children showed at least one just erupted tooth. These cases were collected from 21 public and private schools. Out of these 21 schools, 9 were public institutions and about $25 \%$ survey children belonged to them. Eight hundred seventy nine (45.2\%) children were males. The mean age of the participants was $9.44 \pm 2.44$ years (R: $4-15$ years). The mean height and weight were $134.45 \pm 45.5 \mathrm{~cm}(\mathrm{R}: 59-188 \mathrm{~cm})$ and $33.21 \pm 11.0 \mathrm{~kg}$ (R: $15-95 \mathrm{~kg})$, respectively.

The mean eruption time of maxillary teeth is illustrated in Figure 1. Right 1stmolar (\# 16) showed the minimum eruption time of 6.6 years, followed by left central incisor (\#21) with the mean value of 6.7 years. The last tooth erupted of this jaw was the left 2nd molar (\#27) with mean value of 11.6 years. Mean eruption time of mandibular teeth is demonstrated in Figure 2. The first tooth appeared in this jaw was the right central incisor (\#41) with mean value of 
Figure 1: Mean Eruption time of Maxillary Jaw of Peshawar Children

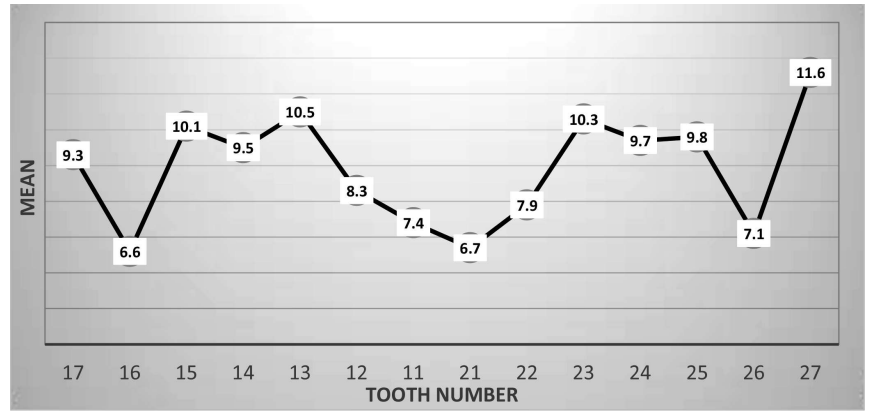

Figure 2: Mean Eruption time of Mandibular Jaw of Peshawar Children

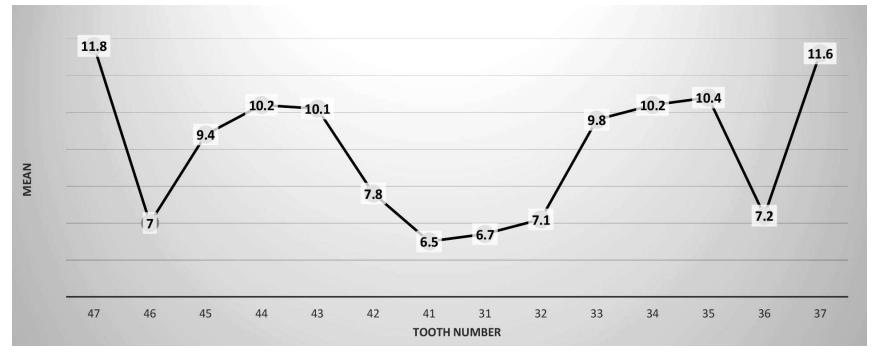

Table 1: Comparison of mean eruption time between male and female children of maxillary jaw

\begin{tabular}{|c|c|c|c|c|}
\hline Tooth Type & Male & \multirow{2}{*}{ Female } & \multirow{2}{*}{ T-Test } & \multirow{2}{*}{ P-Value } \\
\cline { 1 - 3 } First quadrant & & & & \\
\cline { 1 - 3 } Second molar (17vs17) & 10.1 & 8.3 & 3.5550 & 0.0005 \\
\hline First Molar (16vs16) & 7.6 & 6.3 & 0.8615 & 0.4017 \\
\hline Second premolar (15vs15) & 9.6 & 10.7 & 1.5729 & 0.1240 \\
\hline First premolar (14vs14) & 9.5 & 9.4 & 0.2681 & 0.7891 \\
\hline Canine (13vs13) & 11 & 9.8 & 5.2419 & $<0.0001$ \\
\hline Lateral incisor (12vs12) & 8.5 & 8.3 & 0.5990 & 0.5501 \\
\hline Central incisor (11vs11) & 6.7 & 7.7 & 2.7941 & 0.0067 \\
\hline Second quadrant & & & & \\
\hline Central incisor (21vs21) & 6.4 & 6.9 & 1.9316 & 0.0572 \\
\hline Lateral incisor (22vs22) & 8.1 & 7.8 & 0.8760 & 0.3829 \\
\hline Canine (23vs23) & 11.1 & 9.5 & 6.7132 & $<0.0001$ \\
\hline First premolar (24vs24) & 9.6 & 9.8 & 0.5465 & 0.5862 \\
\hline Second Premolar (25vs25) & 10.3 & 9.4 & 1.3914 & 0.1718 \\
\hline First molar (26vs26) & 8.6 & 6.7 & 1.2871 & 0.2144 \\
\hline Second molar (27vs27) & 12.2 & 10.6 & 3.9965 & 0.0001 \\
\hline
\end{tabular}

6.5 years, followed by left central incisor (\#31) with mean value of 6.7 years. The last tooth erupted in this jaw was right 2nd molar (\#47) with mean value of 11.8 years, preceded by left 2 nd molar (\#37) with mean value of 11.6 years. Comparison of eruption time of male and female children of maxillary and mandibular jaws is shown in Table 1 and Table 2, respectively. Among maxillary teeth, the male
Table 2: Comparison of mean eruption time between male and female children of mandibular jaw

\begin{tabular}{|c|c|c|c|c|}
\hline \multicolumn{1}{|l|}{ Tooth Type } & Male & \multirow{2}{*}{ Female } & \multirow{2}{*}{ T-Test } & \multirow{2}{*}{ P-Value } \\
\cline { 1 - 2 } Third quadrant & & & & \\
\cline { 1 - 2 } Central incisor (31vs31) & 6.6 & 6.7 & 0.2299 & 0.8191 \\
\hline Lateral incisor (32vs32) & 6.9 & 7.3 & 1.2995 & 0.1962 \\
\hline canine (33vs33) & 10.3 & 9.2 & 4.2025 & $<0.0001$ \\
\hline First premolar (34vs34) & 10.8 & 9.6 & 4.3730 & $<0.0001$ \\
\hline Second premolar (35vs35) & 11.2 & 9.6 & 3.2887 & 0.0016 \\
\hline First molar (36vs36) & 7.5 & 6.7 & 1.9525 & 0.0537 \\
\hline Second molar (37vs37) & 11.8 & 11.2 & 3.1589 & 0.0017 \\
\hline Fourth quadrant & & & & \\
\hline Second Molar (47vs47) & 12 & 11.2 & 4.3141 & 0.0001 \\
\hline First Molar (46vs46) & 7.2 & 6.6 & 1.3565 & 0.1787 \\
\hline Second premolar (45vs45) & 10.2 & 8.3 & 2.8131 & 0.0068 \\
\hline First premolar (44vs44) & 10.6 & 9.6 & 3.3030 & 0.0012 \\
\hline Canine (43vs43) & 10.7 & 9.6 & 4.4223 & $<0.0001$ \\
\hline Lateral incisor (42vs42) & 7.1 & 8.1 & 2.7101 & 0.0078 \\
\hline Central incisor (41vs41) & 6 & 6.8 & 2.6105 & 0.0115 \\
\hline
\end{tabular}

children showed significantly late eruption as compared to females for right 2nd molar (\#17), right canine (\#13), left canine (\#23), and left 2nd molar (\#27), while female children showed significantly late eruption as compared to males for right central incisor (\#11). Considering mandibular teeth, the male children exhibited significantly late eruption as compared to females for left canine (\#33), left 1st premolar (\#34), left 2nd premolar (\#35), left 2nd molar (\#37), right canine (\#43), right 1st premolar (\#44), right 2nd premolar and right 2nd molar (\#47), while female children showed significantly late eruption as compared to males for right central incisor (\#41) and right lateral incisor (\#42). Table 3 illustrates the simple bivariate and partial correlations of height of the cases, controlling for weight for partial correlation. Out of 14 maxillary teeth, 8 teeth showed significant positive correlation between time of eruption and height of the children, while 10 teeth of mandibular jaw showed significant positive correlation. Eruption time of central incisors and first premolars of both the jaws did not show significant correlation with height of the children. The partial correlation of time of eruption, controlling the weight, of seven teeth was positively correlated with height of the children formaxillary jaw, while nine teeth of mandibular jaw showed the significant positive partial correlations of time of eruption with height, controlling the weight of the children. The sequence of eruption using the mean eruption time emerged as follows: maxillary jaw: first molar - central incisor - lateral incisor - fist premolar - second premolar - canine (3) and second molar (7); mandibular jaw: Central incisor - first molar - lateral incisor - canine - first 
Table 3: Pearson and partial correlation of eruption time with height of the children

\begin{tabular}{|c|c|c|c|c|c|c|c|c|c|c|c|}
\hline \multirow[b]{2}{*}{$\begin{array}{c}\text { Tooth } \\
\text { Type }\end{array}$} & \multirow{2}{*}{$\begin{array}{c}\text { No. } \\
\text { of Cases }\end{array}$} & \multicolumn{2}{|c|}{ Pearson Correlation } & \multicolumn{2}{|c|}{ Partial Correlation } & \multirow[b]{2}{*}{$\begin{array}{c}\text { Tooth } \\
\text { Type }\end{array}$} & \multirow{2}{*}{$\begin{array}{c}\text { No. } \\
\text { of Cases }\end{array}$} & \multicolumn{2}{|c|}{ Pearson Correlation } & \multicolumn{2}{|c|}{ Partial Correlation } \\
\hline & & $\mathbf{R}$ & p-value & $\mathbf{R}$ & p-value & & & $\mathbf{R}$ & p-value & $\mathbf{R}$ & p-value \\
\hline 17 & 138 & 0.556 & $<0.0001$ & .581 & $<0.0001$ & 47 & 363 & .319 & $<0.0001$ & .258 & $<0.0001$ \\
\hline 16 & 18 & 0.742 & $<0.0001$ & .118 & 0.653 & 46 & 83 & .729 & $<0.0001$ & .310 & 0.005 \\
\hline 15 & 40 & 0.023 & 0.888 & .425 & 0.007 & 45 & 57 & .470 & $<0.0001$ & .662 & $<0.0001$ \\
\hline 14 & 104 & 0.376 & $<0.0001$ & 0.168 & 0.090 & 44 & 142 & .162 & .055 & .324 & $<0.0001$ \\
\hline 13 & 240 & 0.016 & 0.803 & -0.119 & 0.660 & 43 & 198 & .159 & .025 & .398 & $<0.0001$ \\
\hline 12 & 139 & 0.173 & 0.420 & .301 & $<0.0001$ & 42 & 117 & .404 & $<0.0001$ & .071 & 0.448 \\
\hline 11 & 71 & 0.136 & 0.258 & .094 & 0.440 & 41 & 59 & .136 & .305 & .098 & 0.466 \\
\hline 21 & 76 & 0.276 & 0.016 & .057 & 0.630 & 31 & 51 & .269 & .056 & .016 & 0.914 \\
\hline 22 & 112 & 0.396 & $<0.0001$ & .066 & 0.491 & 32 & 125 & .291 & .001 & .069 & 0.443 \\
\hline 23 & 240 & 0.240 & $<0.0001$ & .529 & $<0.0001$ & 33 & 212 & .416 & $<0.0001$ & .429 & $<0.0001$ \\
\hline 24 & 87 & 0.198 & 0.066 & .412 & $<0.0001$ & 34 & 173 & .067 & .381 & .474 & $<0.0001$ \\
\hline 25 & 41 & 0.034 & 0.832 & .440 & 0.005 & 35 & 71 & .306 & .009 & .533 & $<0.0001$ \\
\hline 26 & 20 & 0.788 & $<0.0001$ & .301 & 0.211 & 36 & 103 & .740 & $<0.0001$ & .388 & $<0.0001$ \\
\hline 27 & 95 & 0.397 & $<0.0001$ & .400 & $<0.0001$ & 37 & 428 & .375 & $<0.0001$ & .244 & $<0.0001$ \\
\hline
\end{tabular}

Table 4: Pearson and partial correlation of eruption time with weight of the children

\begin{tabular}{|c|c|c|c|c|c|c|c|c|c|c|c|}
\hline \multirow[b]{2}{*}{$\begin{array}{c}\text { Tooth } \\
\text { Type }\end{array}$} & \multirow{2}{*}{$\begin{array}{c}\text { No. } \\
\text { of Cases }\end{array}$} & \multicolumn{2}{|c|}{ Pearson Correlation } & \multicolumn{2}{|c|}{ Partial Correlation } & \multirow[b]{2}{*}{$\begin{array}{c}\text { Tooth } \\
\text { Type }\end{array}$} & \multirow{2}{*}{$\begin{array}{c}\text { No. } \\
\text { of Cases }\end{array}$} & \multicolumn{2}{|c|}{ Pearson Correlation } & \multicolumn{2}{|c|}{ Partial Correlation } \\
\hline & & $\mathbf{R}$ & p-value & $\mathbf{R}$ & p-value & & & $\mathbf{R}$ & p-value & $\mathbf{R}$ & p-value \\
\hline 17 & 138 & .715 & $<0.0001$ & .254 & .003 & 47 & 363 & .374 & $<0.0001$ & .160 & .002 \\
\hline 16 & 18 & .718 & .001 & .291 & .258 & 46 & 83 & .744 & $<0.0001$ & .225 & .042 \\
\hline 15 & 40 & .425 & .006 & .031 & .854 & 45 & 57 & .453 & $<0.0001$ & .117 & .389 \\
\hline 14 & 104 & .382 & $<0.0001$ & .119 & .066 & 44 & 142 & .356 & $<0.0001$ & .042 & .621 \\
\hline 13 & 240 & 0.403 & $<0.0001$ & 0.417 & $<0.0001$ & 43 & 198 & .424 & $<0.0001$ & .001 & .990 \\
\hline 12 & 139 & .343 & $<0.0001$ & .000 & .997 & 42 & 117 & .237 & .010 & .343 & $<0.0001$ \\
\hline 11 & 71 & .135 & .262 & .096 & .430 & 41 & 59 & .163 & .218 & .037 & .782 \\
\hline 21 & 76 & .131 & .258 & .251 & .030 & 31 & 51 & .189 & .184 & .196 & .173 \\
\hline 22 & 112 & .246 & .009 & .327 &.$<0.0001$ & 32 & 125 & .242 & .007 & .180 & .045 \\
\hline 23 & 240 & .565 & $<0.0001$ & .058 & .374 & 33 & 212 & .555 & $<0.0001$ & .157 & .022 \\
\hline 24 & 87 & .449 & $<0.0001$ & .012 & .913 & 34 & 173 & .472 & $<0.0001$ & .081 & .292 \\
\hline 25 & 42 & .408 & .007 & .184 & .256 & 35 & 71 & .578 & $<0.0001$ & .160 & .185 \\
\hline 26 & 20 & .795 & $<0.0001$ & .256 & .291 & 36 & 103 & .756 & $<0.0001$ & .317 & .001 \\
\hline 27 & 95 & .518 & $<0.0001$ & .180 & .038 & 37 & 428 & .406 & $<0.0001$ & .180 & $<0.0001$ \\
\hline
\end{tabular}


Table 5: Pearson and partial correlation of eruption time with BMI of the children

\begin{tabular}{|c|c|c|c|c|c|c|c|}
\hline \multirow[b]{2}{*}{ Tooth Type } & \multirow{2}{*}{$\begin{array}{c}\text { No. } \\
\text { of Cases }\end{array}$} & \multicolumn{2}{|c|}{ Pearson Correlation } & \multirow[b]{2}{*}{ Tooth Type } & \multirow{2}{*}{$\begin{array}{c}\text { No. } \\
\text { of Cases }\end{array}$} & \multicolumn{2}{|c|}{ Pearson Correlation } \\
\hline & & $\mathbf{R}$ & $p$-value & & & $\mathbf{R}$ & p-value \\
\hline 17 & 138 & .296 & $<0.0001$ & 47 & 363 & .118 & .024 \\
\hline 16 & 18 & .411 & .090 & 46 & 83 & .385 & $<0.0001$ \\
\hline 15 & 40 & .295 & .064 & 45 & 57 & .453 & $<0.0001$ \\
\hline 14 & 104 & .216 & .027 & 44 & 142 & .279 & .001 \\
\hline 13 & 240 & 0.299 & 0.001 & 43 & 198 & .281 & $<0.0001$ \\
\hline 12 & 139 & .221 & .009 & 42 & 117 & .030 & .749 \\
\hline 11 & 71 & .068 & .574 & 41 & 59 & .084 & .528 \\
\hline 21 & 76 & .123 & .289 & 31 & 51 & .005 & .972 \\
\hline 22 & 112 & .089 & .350 & 32 & 125 & .108 & .231 \\
\hline 23 & 240 & .287 & $<0.0001$ & 33 & 212 & .316 & $<0.0001$ \\
\hline 24 & 87 & .345 & .001 & 34 & 173 & .321 & $<0.0001$ \\
\hline 25 & 42 & .355 & .023 & 35 & 71 & .249 & .036 \\
\hline 26 & 20 & .408 & .074 & 36 & 103 & .415 & $<0.0001$ \\
\hline 17 & 95 & .167 & .106 & 37 & 428 & .131 & .007 \\
\hline
\end{tabular}

Figure 5: Comparison of time of eruption of children of current study with other selected studies from other countries

\begin{tabular}{|c|c|c|c|c|c|c|c|c|c|c|c|c|}
\hline \multicolumn{7}{|c|}{ Asia } & \multicolumn{3}{|c|}{ Europe } & \multicolumn{2}{|c|}{ Africa } & \multirow{2}{*}{$\begin{array}{l}\text { Australasia } \\
\text { New } \\
\text { Zealand } \\
(2012)\end{array}$} \\
\hline Maxillary & $\begin{array}{l}\text { Current Study } \\
\text { Peshawar } \\
\text { Pakistan }\end{array}$ & $\begin{array}{l}\text { Karachi } \\
\text { Pakistan } \\
\text { (2011) }\end{array}$ & $\begin{array}{l}\text { Basra Iraq } \\
(2016)\end{array}$ & $\begin{array}{l}\text { Kota Bharu } \\
\text { Malaysia } \\
(2007)\end{array}$ & $\begin{array}{l}\text { Mangalore } \\
\text { Indian } \\
(2016)\end{array}$ & $\begin{array}{l}\text { Turkey } \\
(2012)\end{array}$ & $\begin{array}{l}\text { Spain } \\
\text { (2013) }\end{array}$ & $\begin{array}{l}\text { Lithuania } \\
\text { (2012) }\end{array}$ & $\begin{array}{l}\text { Czechoslovakia } \\
\text { (2017) }\end{array}$ & $\begin{array}{l}\text { Uganda } \\
\text { (2013) }\end{array}$ & $\begin{array}{l}\text { Nigeria } \\
(\mathbf{2 0 1 4})\end{array}$ & \\
\hline CI & 7.05 & 7.7 & 6.5 & 6.8 & 7.3 & 7.3 & 7.5 & 6.89 & 7.0 & 6.2 & 6.67 & 7.30 \\
\hline LI & 8.1 & 8.4 & 7.5 & 8.2 & 8.2 & 8.5 & 8.9 & 7.96 & 8.0 & 7.8 & 7.87 & 8.43 \\
\hline $\mathrm{CN}$ & 10.4 & 10.9 & 11 & 11.2 & 11.7 & 10.7 & 11.9 & 11.09 & 11.3 & 10 & 10.69 & 11.52 \\
\hline FPM & 9.6 & 10.1 & 9 & 9.8 & 10.6 & 9.7 & 11.4 & 9.91 & 9.5 & 9.4 & 9.99 & 11.03 \\
\hline SPM & 9.95 & 10.35 & 10 & 10.8 & 11.7 & 10.0 & 11.7 & 10.83 & 11.0 & 9.8 & 10.91 & 11.86 \\
\hline FM & 6.85 & 6.65 & 6 & 6.7 & 6.6 & 6.4 & 7.5 & 6.41 & 6.9 & 5.8 & 6.05 & 6.64 \\
\hline SM & 10.45 & 11.8 & 12 & 12.4 & 12.1 & 10.6 & 12.6 & 12.31 & 12.7 & 10.9 & 11.81 & 12.49 \\
\hline \multicolumn{13}{|c|}{ Mandibular } \\
\hline CI & 6.6 & 6.95 & 6 & 6.6 & 6.7 & 6.4 & 7.2 & 6.13 & 6.4 & 6.4 & 5.47 & 6.51 \\
\hline LI & 7.45 & 7.85 & 7 & 7.4 & 7.9 & 7.3 & 8.6 & 7.2 & 7.3 & 6.0 & 6.79 & 7.62 \\
\hline $\mathrm{CN}$ & 9.95 & 10.15 & 9.5 & 10.2 & 10.5 & 10.0 & 10.9 & 10.37 & 9.4 & 9.8 & 9.98 & 10.57 \\
\hline FPM & 10.2 & 10.4 & 9.5 & 9.95 & 10.6 & 9.9 & 11.5 & 10.12 & 10.0 & 9.6 & 10.04 & 10.88 \\
\hline SPM & 9.9 & 10.65 & 10.5 & 10.8 & 10.9 & 10.4 & 11.7 & 11.06 & 10.9 & 9.2 & 10.69 & 11.89 \\
\hline FM & 7.1 & 6.55 & 6 & 6.4 & 6.2 & 6.5 & 8.3 & 6.21 & 6.5 & 5.9 & 5.68 & 6.53 \\
\hline SM & 11.7 & 11.35 & 11 & 11.4 & 12.1 & 11.0 & 11.9 & 11.69 & 12.4 & 10.5 & 11.41 & 11.95 \\
\hline
\end{tabular}


premolar - second premolar and second molar.

Simple bivariate and partial correlations of time of eruption with weight, controlling for height of the children for later correlation is depicted in Table 4. Out of 28 teeth, only 4 teeth did not show significant Pearson correlations between time of eruption and weight. However only 12 teeth showed significant partial correlations between time of eruption and weight, controlling the height. The Pearson correlation between time of eruption and body mass index of the children is shown in Table 5. Seventeen teeth, 7 in maxillary jaw and 10 in mandibular jaw, showed positive significant correlation between time of eruption and body mass index.

\section{DISCUSSION}

Authors could not find any study on this topic for this province in the literature, therefore this was first study conducted in Khyber Pakhtunkhwa province of Pakistan to investigate the time and sequence of emergence of permanent teeth. Since the main objective of the study was to find out the time and sequence of emergence of permanent teeth of the children of this province and the secondary objectives were to observe the effect of gender, weight, height and BMI on eruption timing, therefore the schools were not divided into different socio-economic groups. However, of choosing the schools using systematic random procedure has reduced any bias due to such co-factors.

The sequence of emergence in maxillary teeth was: first molar (6) - central incisor (1) - lateral incisor (2) - fist premolar (4) - second premolar (5) - canine (3) and second molar (7). This sequence agrees with studies of Khan ${ }^{2}$ (Karachi, Pakistan), Lakhshamppa et $\mathrm{al}^{10}$ (India), del Cojo et $\mathrm{al}^{16}$ (Spain), Ahmed and Al-Dahan ${ }^{7}$ (Basra, Iraq), Almonaitiene R et al17(Lithuania), Dashash and Al-Jazar ${ }^{14}$ (Syria) and Shaweesh ${ }^{12}$ (Jordan). However, Upadhyay ${ }^{13}$ (Nepal), Mahmood et $\mathrm{al}^{3}$ (Rawalpindi, Pakistan), Oziegbe et $\mathrm{al}^{21}$ (Nigeria) and Šindelárová ${ }^{18}$ (Czechoslovakia) have shown the sequence of eruption as 6-1-2-4-3-5-7. Their studies showed that canine erupted earlier than $2 \mathrm{nd}$ premolar. The sequence of emergence of mandibular teeth in this study was 1-6-2-3-4-5-7. This sequence matches with a study of del Cojo et al $^{16}$, Ahmed and Al-Dahan ${ }^{7}$ and Sindelarova et al. ${ }^{18}$ HoweverAlmonaitiene ${ }^{17}$, Dashash and Al-Jazar ${ }^{14}$ and Oziegbe ${ }^{21}$ showed that sequence of eruption was the same as this study in their respective population of Lithuania, Syria and Nigeria, except that first premolar erupted earlier than canine. Shaweesh ${ }^{12}$, Mahmood et $\mathrm{a}^{13}$, and Upadhayay ${ }^{13}$ indicated that the children of their respective population of Jordan, Pakistan (Rawalpindi) and India showed the same sequence of eruption as our study except first molar erupts earlier than central incisor.

First tooth emerged among the permanent dentition was the mandibular right central incisor (\#41) with mean age of 6.5 years. This value is almost the same as Caucasian children of $\mathrm{UK}^{19}$, Jordan ${ }^{1}$, and India ${ }^{10}$;lower than the children of Karachi (Pakistan) ${ }^{2}$, Syria ${ }^{14}$, Malaysia ${ }^{9}$, Sri Lankan ${ }^{27}$, Nepal $^{13}$, Nigeria ${ }^{21}$, Uganda ${ }^{20}$ and Span ${ }^{16}$; but higher than Rawalpindi(Pakistani) ${ }^{3}$, Iraqi ${ }^{7}$, Czechoslovakian18, Lithuanian ${ }^{17}$ children. The last tooth emerge in mandibular jaw in this study was right 2 nd molar (\#47) with the mean age of 11.8 years. This value is almost the same as Jordanian1children; higher than Karachi (Pakistan) ${ }^{2}$, Rawalpindi (Pakistan) ${ }^{3}$, Syrian ${ }^{14}$, Uganda ${ }^{20}$, Nigerian $^{21}$, Iraqi $^{7}$ andMalaysia ${ }^{9}$ children; but lower than Caucasian children of UK ${ }^{19}$, Czechoslovakian ${ }^{18}$, Neapli $^{13}$, Spanish ${ }^{16}$, Lithuanian ${ }^{17}$ and Indian ${ }^{10}$ children.

The first emerge tooth in maxillary jaw was right first molar (\#16) with mean age of 6.6 years. It is almost the same as Karachi (Pakistan) ${ }^{2}$, Malaysia ${ }^{9}$ and Caucasian children of $\mathrm{UK}^{19}$ children; lower than Syrian ${ }^{14}$, Czechoslovakian ${ }^{18}$, Spanish ${ }^{16}$ and Nepali ${ }^{13}$ children; but higher than Rawalpindi (Pakistan) ${ }^{3}$, Iraqi ${ }^{7}$, Nigerian ${ }^{21}$, Uganda $^{20}$, Jordanian ${ }^{1}$, Indian ${ }^{10}$ and Lithuanian ${ }^{17}$ children. The last tooth emerged in mandibular jaw was left 2nd molar (\#27) with mean value of 11.6 years. This value is almost the same as Malaysia ${ }^{9}$ children; lower than Jordanian1, Karachi (Pakistan) $)^{1}$, Indian ${ }^{10}$, Lithuanian ${ }^{17}$, Czechoslovakian ${ }^{18}$, Caucasian children of UK ${ }^{19}$, Spanish ${ }^{16}$, Iraqi ${ }^{7}$ and Nepali ${ }^{13}$ children; but higher than Rawalpindi (Pakistan) ${ }^{3}$, Syrian $^{14}$, Nigerian ${ }^{21}$, Uganda $^{20}$ children.

Out of 28 teeth observed, females showed early eruption in 20 teeth as compared to males. However, only 12 of them were statistically significant. Out of those 8 teeth, where males showed early eruption, 3 of them were statistically significant. These eight teeth were: all four central incisors, maxillary right second molar and maxillary left first premolar, mandibular left and right lateral incisors. Therefore, this study does not show clear cut directions that gender does affect in early or late eruption. Nevertheless, most of studies ${ }^{17,17,18,19,21,9}$ showed early eruption for girls as compared to boysfor all the teeth. However, some studies ${ }^{2,3,10,13,14,16,20}$ do not show a clear cut direction of eruption of teeth by males or females. All the European countries children, except Spanish showed early eruption in girls. All the Indian subcontinent countries do not show this feature of early eruption of girls as compared to boys for all the teeth.

Pearson correlation showed positive correlation of time of eruption with height, but only 14 of them were statistically significant, while 24 teeth, except the central incisors, showed statistically significant positive correlation with weight of the children. However, seventeen teeth showed statistically 
significant partial correlation of time of eruption with height, keeping the weight as control, while only 12 teeth showed significantly positive correlation of time of eruption with weight, keeping the height as control. Pearson correlation of time of eruption for 17 teeth showed statistically significant positive correlation with BMI. These results indicate that weight of the children affects the eruption timing more than height of the children. These results do not match with the study of Khan for Karachi children. ${ }^{2} \mathrm{He}$ showed that the time of eruption of almost all the teeth were significantly correlated with height of the children, while 26 teeth were significantly correlated with height keeping the weight as control. Fifty percent of the teeth were correlated with weight of the children, while only 5 teeth were significant correlated with weight keeping height as control. Furthermore, only $25 \%$ of the teeth were significantly correlated with BMI. Kutesa et al ${ }^{20}$ showed that in Ugandan children only one tooth showed significant relation with height while controlling the weight. However, 16 teeth showed significant correlation with weight keeping height as control. Noori et $\mathrm{al}^{28}$ showed that eruption time are correlated with height and weight of children in less number of teeth as compared to this study. Therefore, surprisingly this study agreed more for correlations of time of eruption with height and weight of Ugandan children than Iraqi and Karachi children. Hence the taller children of Peshawar showed late eruptions compared to shorter children.

This study showed that children of Peshawar indicated early eruption than the children of Karachi (Pakistan), India, Spain, Czechoslovakia (Maxillary jaw) and Australia; while late eruption than the children of Uganda, Nigeria and Czechoslovakia (Mandibular jaw). However, there were no clear cut trend for time of eruption with Iraqi, Malaysian, Turkey and Lithuanian children. Therefore, Peshawar's children showed late eruption than African children, but do not show any clear picture of other genetic background. Since the schools were chosen from urban or peri-urban areas pf Peshawar and the rural areas children could have difference diet and life style patterns and hence the time of eruption could be different. As it was mentioned in the Introduction that the text books of dentistry contain the information of time of eruption from European and American standards. These nationwide studies could be used as standard for Pakistani children. Treatment management and class lectures could be arranged on the basis of these information.

\section{CONCLUSIONS}

Study concludes that children of Peshawar showed early eruption than the children of Karachi and India, however late eruption as compared to African children. These children did not show any clear cut trend with other ethnic background. This study also agreed with most of the other countries studies that eruption of girls are earlier than boys.

\section{CONFLICT OF INTEREST}

None declared

\section{REFERENCES}

1. Shaweesh AI. Timing and sequence of emergence of permanent teeth in the Jordanian population. Arch Oral Bio. 2012;57:122-30 https://doi.org/10.1016/j.archoralbio.2011.08.014

2. Khan N. Eruption time of permanent teeth in Pakistani children. Iranian J Publ Health 2011; 40: 63-73.

3. Mahmood A, Hamid W, Jabbar A, Farooq A. Ages and sequence of eruption of permanent teeth in a sample of Pakistani school children. Pak Orthodontic J. 2010;2:52-9.

4. Khan NB, Chohan AN, 1-Magrabi B, Al-Deyab S, Zahid T, Al-Moutairi M. Eruption time of permanent first molars and incisors among a sample of Saudi male schoolchildren. Saudi Dent J 2006, 18: $18-24$.

5. Chohan AN, Khan NB, Al Nahedh L, Bin Hassan M, Al Sufyani $\mathrm{N}$. Eruption time of permanent first molars and incisors among female primary school children of Riyadh. J Dow Univ Health Sc, 2007:1: 53-58.

6. Khan N, Chohan AN, Al Nasser F, Al Sharani D, Al Jorais R, Al Salehi R, Al Yousef T. Statistical presentation of eruption age of permanent second molars, premolars and canines in female school children living in Riyadh, Saudi Arabia. Saudi Dent J 2008, 20:14049.

7. Ahmed HS, Al-Dahan ZA. Time of emergence of permanent teeth and impact of nutrition status among 4-15 years old children and teenagers in Basra City/Iraq. Bagh Coll Dent 2016; 28:134-40. https://doi.org/10.12816/0033224

8. Heinrich-Weltzien R, Zorn C, Monse B, Kromeyer-Houschild K. Relationship between Malnutrition and the number of permanent teeth in Filipino 10- to 13-year-olds. BioMed Res Int 2013; 2013; 205950. https://doi.org/10.1155/2013/205950

9. Hussin AS, Mokhtar N, Naing L, Taylor JA, Mahmood Z. The timing and sequence of emergence of permanent teeth in Malay schoolchildren in Kota Bharu, Malaysia. Arch Orofacial Sc. 2007, 2: 36-40.

10. Lukshmappa A, Guledgud MV, Patil K. Eruption times and patterns of permanent teeth of school children of India. Indian J Dent Res 2011; 22:755-63.

https://doi.org/10.4103/0970-9290.94568 
11. Bagewadi NB, Kumar H, Bagewadi SB, Kumar V, Panchmal GS, Mohnish ZM. Comparison of chronology of teeth eruption with body mass index among school children at Mangalore: A cross-sectional study. J Indian Assoc Pub Health Dent 2016;14:276-80. https://doi.org/10.4103/2319-5932.189835

12. Shaweesh AI. Timing and sequence of emergence of permanent teeth in the Jordanian population. Arc Oral Bio 2012; 57:122-130. https://doi.org/10.1016/j.archoralbio.2011.08.014

13. Upadhyay S, Shrestha R, Shrestha D, Poudyal S. Permanent Teeth Emergence Time and Sequence in Children of Kavre District, Nepal. Kathmandu Univ Med J 2016;55: 269-73

14. Dashash M, Al-Jazar N. Timing and sequence of permanent teeth in Syrian schoolchildren. J Investigative Clin Dent 2017;9: https://doi.org/10.1111/jicd.12311

15. Bayrak S, Sen Tunc E, Tuloglu N, Acikgoz A. Timing of permanent teeth eruption in Turkish children. J Clin Ped Den 2012; 37: 207-211. https://doi.org/10.17796/jcpd.37.2.8v072017534j0191

16. Del Cojo MB, Lopez NEG, Martinez MRM, Garcia MJN. Time and sequence of eruption of permanent teeth in Spanish children. European J Paedi Dent 2013;14:101-03.

17. Almonaitiene R, Balciuniene I, Tutkuviene J. Standards for permanent teeth emergence time and sequence in Lithuanian children, residents of Vilnius city. Stomalologia, Baltic Den Maxillofacial J 2012: 14:93-100.

18. Šindelárová R, Žáková L, and Broukal Z. Standards for permanent tooth emergencein Czech children. BMC Oral Health 2017;17:14047.

https://doi.org/10.1186/s12903-017-0427-9

19. Elmes A, Dykes E, Cookson MJ. A cross-sectional survey to determine the ages of emergence of permanent teeth of Caucasian children of the Colchester area of the UK. Br Dent J 2010; 209:E10. https://doi.org/10.1038/sj.bdj.2010.672
20. Kutesa A, Nkamba EM, Muwazi L, Buwembo W, Rwenyonyi $\mathrm{CM}$, Weight, height and eruption times of permanent teeth of children aged 4-15 years in Kampala, Uganda. BMS Oral Health 2013; 13:1522 .

https://doi.org/10.1186/1472-6831-13-15

21. Oziegbe EO, Esan TA, Oyedele TA. Brief communication: Emergence chronology of permanent teeth in Nigerian children Am J Phys Anthropology 2014;153:500-511. https://doi.org/10.1002/ajpa.22447

22. Nonong YH, Epsilawati L. Assessment of dental emerge base on age in Sundanese people using panoramic radiograph. Int J Sc Res 2016; 5:303-305.

https://doi.org/10.21275/v5i3.NOV161829

23. Sánchez-Pérez L, Irigoyen M, Zepeda M. Dental caries, tooth eruption timing and obesity: a longitudinal study in a group of Mexican schoolchildren. Acta Odontologica Scandinavica, 2010; 68:57-64 https://doi.org/10.3109/00016350903449367

24. Kanagaratnam S, Schluter PJ. The age of permanent tooth emergence in children of different ethnic origin in the Auckland region: a crosssectional study. N Z Dent J. 2012;108:55-61.

25. Shourie KL. Eruption age of teeth in India. Ind J Med Res. 1946: 34:105-18

26. Saleemi MA, Hägg U, Jalil F, Zaman S. Timing of emergence of individual primary teeth. A prospective longitudinal study of Pakistani children. Swed Dent J 1994. 18:107-12.

27. Vithanaarachchi VSN, Nawarathne LS, Wijeyeweera RL. Eruption times and patterns of permanent teeth in Sri Lankan school children in Western province. Sri Lanka Dent J 2018; 48(01): 25-31

28. Noori AJ, Hussein SH, Ali DA. Height, weight and number of erupted permanent teeth among 6-16 years old children in Sulaimani City. Sulaimani Dent J 2015; 2:61-66.

https://doi.org/10.17656/sdj.10040, 